\title{
Preliminary observations on the distribution and status of dwarf blue sheep Pseudois schaeferi
}

\author{
Xiao-ming Wang, Ji-tai Peng and Hua-ming Zhou
}

\begin{abstract}
Dwarf blue sheep Pseudois schaeferi are known to survive only in Batang County, Ganzi Tibetan Autonomous Prefecture, Sichuan Province, China. According to the results of a survey between 19 November and 21 December 1997, the species has declined steeply in both range and numbers since the 1950s and 1960s because of excessive hunting. The survey found that dwarf blue sheep were concentrated on steep cliffs between 2700 and $3200 \mathrm{~m}$. In the area near Batang, the
\end{abstract}

species's range was estimated to cover $295 \mathrm{sq} \mathrm{km}$ and the population to number c. 200 individuals. The average group size was 6.2 individuals, with a male : female ratio of $67.7: 100$. The authors recommend that the species be included in Class I of the National List of Protected Animals in China.

Keywords Batang County of China, conservation status, distribution, dwarf blue sheep, Pseudois schaeferi.

\section{Introduction}

The dwarf blue sheep Pseudois schaeferi was discovered by Schafer in 1937, in Batang County of Sichuan Province, China. Although Schafer believed that he had discovered a new form, he did not name it, nor did Engelmann (1938) who later analysed Schafer's data. Allen (1940) did not consider it a separate species but simply an ordinary blue sheep $P$. nayaur of small size, while Haltenorth (1963) gave it subspecific rank. From comparisons of body and horn size, skull measurements and habitat for the typical and dwarf forms of blue sheep, Groves (1978) decided that the 'distinctiveness and isolation of the dwarf blue sheep...suggest that, as a provisional measure at least, it should be classified as a full species...'. While this designation has been followed by others (e.g. Wu et al., 1990; Hu, 1994; IUCN, 1996), the taxonomic status of dwarf blue sheep remains uncertain (Schaller, 1998). Tibetans distinguish between the two types of blue sheep in Batang, using the name rong-na to describe the dwarf form (in $\mathrm{Ti}$ betan, rong means a low and warm mountain and na means sheep or goat). The name gong-na is used for the typical blue sheep (gong means high mountain in Tibetan).

The dwarf blue sheep is currently listed as Endangered (A2d, B1 + 2e) by IUCN (1996), even though its

\footnotetext{
Xiao-ming Wang (corresponding author) Department of Biology, East China Normal University, Shanghai 200062, People's Republic of China. E-mail: wxming@public3.sta.net.cn
}

Ji-tai Peng and Hua-ming Zhou Ganzi Forest Bureau, Kangding 62600 , Sichuan, People's Republic of China.

Received 15 March 1998. Accepted 9 February 1999 status is not clear (Shackleton, 1997). The available literature on the dwarf blue sheep is scant (Wang \& Hoffman, 1987; Wu et al., 1990). In this paper, we present preliminary information on the species collected during a survey conducted in 1997. Our survey results provide the first detailed information on the recent distribution and status of the dwarf blue sheep.

\section{Methods}

We carried out a survey in the Ganzi Tibetan Autonomous Prefecture $\left(97^{\circ} 26^{\prime}-104^{\circ} 27^{\prime} \mathrm{E}\right.$ and $27^{\circ} 57^{\prime}-$ $\left.34^{\circ} 21^{\prime} \mathrm{N}\right)$ of Sichuan Province, China, between 19 November and 21 December 1997. The survey focused mainly on the status of large mammals in this area, including the past (Schafer, 1937) and present range of the dwarf blue sheep. We travelled c. $3000 \mathrm{~km}$ within an area of $c .35,000 \mathrm{sq} \mathrm{km}$ that included 10 counties: Kangding, Danba, Daofu, Xinlong, Luhe, Ganzi, Shiqu, Dege, Beiyu, Batang, Litang and Yajiang (Fig. 1). The area is mountainous, and ranges from rolling uplands to glaciated ranges and deep valleys. Much of the area is over $4000 \mathrm{~m}$, but near the Yangtze (Changjiang) River it falls to $c .2200 \mathrm{~m}$. The climate is harsh and dry, with average temperatures of $9-15^{\circ} \mathrm{C}$ in July and -3 to $-12^{\circ} \mathrm{C}$ in January. Annual precipitation is about $650 \mathrm{~mm}$, with most falling between June and September.

Within this region, Batang County is a semi-agricultural and semi-pastoral area covering c. $6255 \mathrm{sq} \mathrm{km}$, with a human population density of 5.8 individuals persq $\mathrm{km}$. It has an average annual temperature of $12.4^{\circ} \mathrm{C}$ and a mean annual precipitation of $467 \mathrm{~mm}$. During the survey, we interviewed local wildlife personnel, pastoralists, hunters and others about dwarf 
blue sheep, and searched suitable sites on foot or horseback along the gorge of the upper Yangtze River and its tributary valleys (Plate 1). All observations were made using $8 \times$ binoculars and a $20 \times$ Kowa spotting scope (Plate 2). When a group of dwarf blue sheep was sighted, we recorded the number of animals and, if possible, the sex and age composition. An estimate of total population size was made using our counts and information from local hunters.

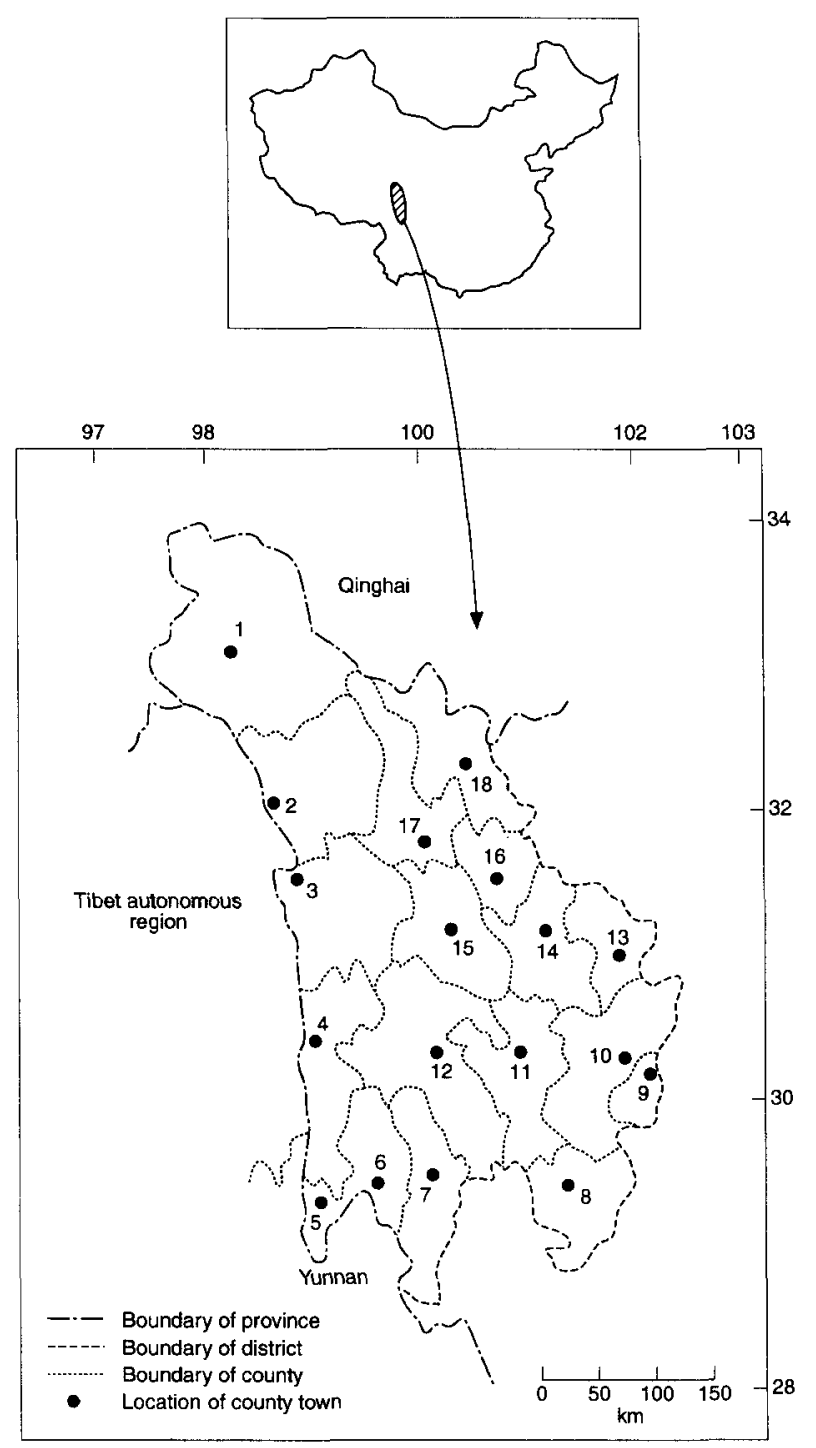

Fig. 1 Map showing the location and boundaries of the counties of Ganzi Tibetan Autonomous Prefecture, Sichuan Province, China. 1, Shiqu; 2, Dege; 3, Beiyu; 4, Batang; 5, Derong; 6, Xiangcheng; 7, Daocheng; 8, Jiulong; 9, Luding; 10, Kangding; 11, Yajiang; 12, Litang; 13, Danba; 14, Daofu; 15, Xinlong; 16, Luhe; 17, Ganzi; 18, Sheda.

\section{Results and discussion}

\section{Distribution and numbers}

Although Schafer (1937) referred to the dwarf blue sheep as one isolated population, he did not define its range except to observe that it occurred near Batang. Allen (1940) noted only that these (sheep) lived in the deep gorge of the upper Yangtze, near Leh (=Shumogo, a small gully) and Drupalong (=Zhubalong)'. Therefore, Groves (1978) wrote, 'how far along the Yangtze gorge the dwarf blue sheep habitat extends is not stated'. Wang et al. (1997) gave an approximate distribution of the dwarf blue sheep as 'part of the upper reaches of the Changiiang (Yangtze) River', based on work by Cai et al. (1990) and $\mathrm{Wu}$ et al. (1990).

According to our survey, the dwarf blue sheep is currently restricted to a small area near the steep, arid, lower slopes of the Yangtze River in Batang County of Sichaun Province, and the very small area of Mukang county on the other side of the river in the Tibet Autonomous Region (Fig. 2). In addition, Groves (1978), based on previous work, described the distribution to be 'from a little north of Batang'. However, we found no evidence that the dwarf blue sheep occurs north of Batang. Cai et al. (1990) suggested that dwarf blue sheep existed in Beiyu County about $100 \mathrm{~km}$ north of Batang, but we were unable to confirm this. The animals in that region are typical blue sheep $P$. nayaur. Hu (1994) reported dwarf blue sheep in Deqing County of Yunnan Province and Derong County of Sichuan Province, far to the south of Batang, but he did not survey these areas, and neither did we.

Based on the information we were able to collect, dwarf blue sheep currently appear to occur principally between the villages of Suwalong and Zhubalong (Fig. 2), $40 \mathrm{~km}$ south-west of the town of Batang. Most dwarf blue sheep were concentrated in an area estimated to be about $295 \mathrm{sq} \mathrm{km}$. All animals that we observed were on very steep rocky slopes $\left(70-80^{\circ}\right)$ at $2700-2900 \mathrm{~m}$. At this elevation, the valleys are dry with a sparse cover of grasses (Cymbopogon distans, Themeda hooderi), low shrubs (Berberis spp., Rosa spp, Cotoneaster spp., Cladrastris spp., Ephedra spp., Rhododendron spp.) and the clubmoss Selaginella sanguinolenta. Local hunters told us that the dwarf blue sheep can also be seen between 2900 and $3200 \mathrm{~m}$ below the forest zone but that they are not present in oak forests. Pseudois nayaur occurred on the same mountain range above $3200 \mathrm{~m}$ up to the alpine meadows. We estimated that there were about 200 dwarf blue sheep in the area between Suwalong and Zhubalong 
Plate 1 The main dwarf blue sheep study area along the upper Yangtze River, Batang County, Sichuan, China (C Xiao-ming Wang).

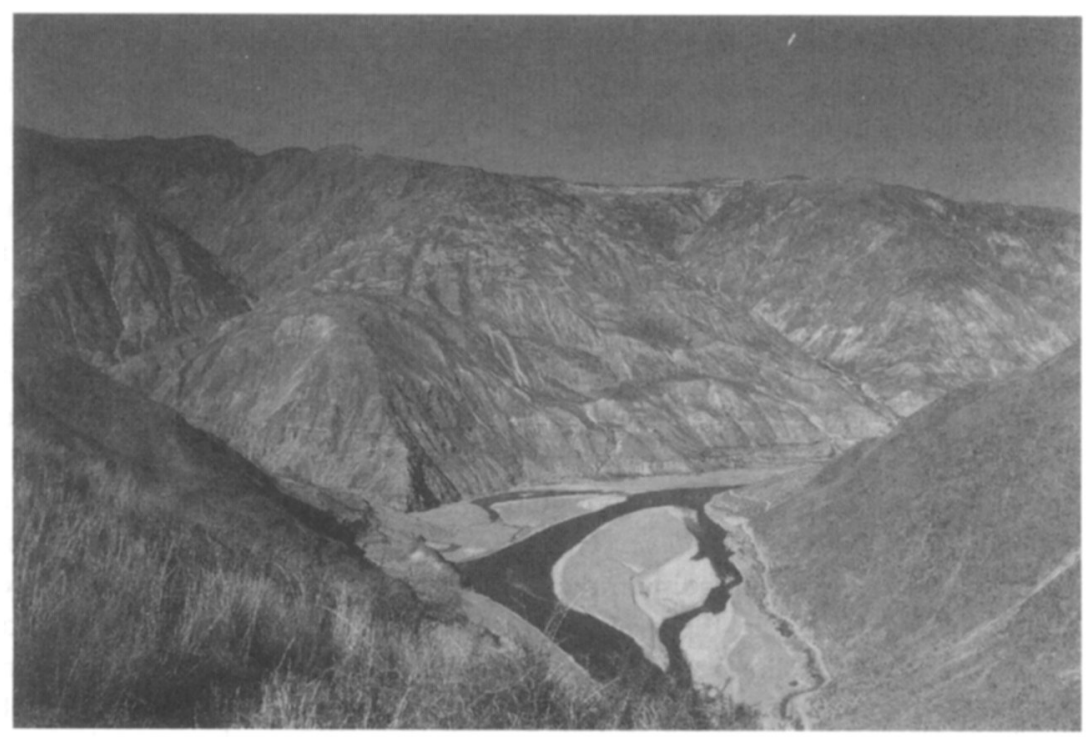

villages. Outside this area, a few dwarf blue sheep have been reported by local people in Dengbo village in Batang County (Fig. 2).

\section{Herd size and composition}

We observed a total of 91 dwarf blue sheep in 14 groups during our survey. In addition, two of us (J.T.P. and H.M.Z.) observed 51 individuals in nine groups in the same area in March 1997. The largest group observed comprised 15 individuals and the smallest two individuals. Schafer (1937) reported that solitary animals were common, but neither Wu et al. (1990) nor the present authors saw lone individuals. Among the 142 sheep observed, the average group size was $6.2 \pm 0.8 \mathrm{SE}$ (range 2-15; Fig. 3). Overall, we recorded 21 males (14.8 per cent), 31 females ( 21.8 per cent) and 11 young ( 7.7 per cent), as well as 79 animals ( 55.6 per cent) for which we were unable to determine sex. Local informants told us that the largest group they had seen was of 25 individuals, but that was in the 1950s and average herd size had declined since, largely as a result of excessive hunting and partly because of some habitat loss.

Among the 63 dwarf blue sheep classified by sex and age, the male : female ratio was $67.7: 100$ and the ratio of young to females (adult and yearling) was $35.5: 100$. For groups where age-sex composition could be determined, we recognized three types: all-male groups, maternal groups (females and young) and mixed groups (males and females with or without young).

\section{Behaviour}

During an 8-h observation period on 12 December 1997, one group of eight dwarf blue sheep remained bedded on a small section of cliff between 11.30 and 14.45 hours, and fed and rested within a $0.5-\mathrm{sq}-\mathrm{km}$ area during the entire period. Our observations suggested that the dwarf blue sheep's principal food was grass (e.g. Pennisetum flaccidum, Setarica glauca) and other plants (e.g. the clubmoss S. sanguinolenta).

We did not observe mating behaviour but, according to local informants, the rutting season of the dwarf blue sheep occurs between mid-November and mid-December. We were also told that females give birth, usually to one young, between late May and late June, and that the wolf Canis lupus, red dog Cuon alpinus, leopard Panthera pardus and large raptors are the sheep's main predators.

\section{Morphology}

The weight of dwarf blue sheep has been reported as $28-39 \mathrm{~kg}$ for males and $25 \mathrm{~kg}$ for females (Schafer, 1937; Allen, 1940), while Wu et al. (1990) reported one female that weighed $35 \mathrm{~kg}$. According to our informants, males are estimated to weigh $34-44 \mathrm{~kg}$ with a maximum of $65 \mathrm{~kg}$. For comparison, the weights of male and female $P$. nayaur are reported to be $50-74.5$ and $44.5-50 \mathrm{~kg}$ in Sichuan ( $\mathrm{Hu}, 1994)$ and $60-75$ and $35-45 \mathrm{~kg}$ in Tibet (Schafer, 1937), respectively.

We measured one male dwarf blue sheep skull in Suwalong village. The basal circumference of the horn was $23 \mathrm{~cm}$ and the length $41 \mathrm{~cm}$. Judging by the annual horn rings, the individual was 4.5 years old. For comparison, seven horn measurements of the typical form of blue sheep aged 7.5-14.5 years were taken from specimens in the Ganzi Museum of Rare and Endangered Wildlife in Kangding. The average basal circumference was $23.8 \pm 1.9 \mathrm{SE} \mathrm{cm}$ (range 13-27) and the 
average length was $54.2 \pm 3.2 \mathrm{SE} \mathrm{cm}$ (range 41-65). Thus, although the total sample size is very small, there appears to be little difference in horn size between the two forms of blue sheep.

\section{Conservation}

Ganzi Tibetan Autonomous Prefecture is famous for the number and variety of its large mammals, such as white-lipped, or Thorold's, deer Cerous albirostris, takin Budorcas taxicolor, giant panda Ailuropoda melanoleuca, snow leopard Panthera uncia and golden snub-nosed monkey Rhinopithecus roxellana. There are at least 33 species of endangered large mammals protected by the Chinese Government in the prefecture. All these large mammals have declined since the 1950s because of habitat fragmentation and illegal killing. Such activities continue today. For example, four snow leopards were killed in 1996 at Zhengda village in Shiqu County. The production of musk and antler velvet in the prefecture started first in Sichuan in the 1950s and continued into the 1980s (Shi \& Chao, 1982). Timber production in the prefecture also started in the 1950 s and the decline in forest resources is now forcing logging operations to move further west. In spite of its extraordinary biodiversity, few zoologists have visited the region.

The prefecture covers about $153,000 \mathrm{sq} \mathrm{km}$ and, while human population density is only about 5.4 individuals per sq km (Anon, 1994), human pressure is pervasive. Valleys are cultivated up to elevations of $3900 \mathrm{~m}$ and livestock are grazed to the limit of vegetation at $4800 \mathrm{~m}$, especially near the Yangtze River. Within the habitat of the dwarf blue sheep there are no areas to which the animals can escape from humans and their livestock.
Agricultural activities are focused mainly in the lower altitudes near the Yangtze River.

Within the range of the dwarf blue sheep in Batang County, a prefectural reserve of about $142.4 \mathrm{sq} \mathrm{km}$ (Fig. 2) was established for the species in 1995 (Peng, 1995). However, activities such as illegal hunting, livestock grazing and mushroom collecting continue within the reserve. We met several local hunters in dwarf blue sheep habitat during our survey. Local hunters occasionally hunt the animal, as do officials from the nearby town, although it is illegal to do so. Foreign hunters shot a total of four male dwarf blue sheep in 1996 and 1997 after the prefecture initiated a hunting programme in an attempt to help support conservation. However, the reserve is not yet staffed or managed because of the lack of financial support and trained workers. It is essential to establish national and international support for the conservation of dwarf blue sheep habitat and other endangered mammals in the Ganzi Prefecture.

The Ganzi Forest Bureau has made a major effort to reduce the illegal hunting of dwarf blue sheep. Unfortunately, it is difficult to enforce regulations, in part because the dwarf blue sheep is not formally on the national list of protected species. The species was considered to be $P$. nayaur and placed in Class II when the List of Key Species of Wildlife Protected under the State Wildlife Protection Law was established in 1988. Consequently, it is both urgent and necessary to eliminate detrimental human activities if the dwarf blue sheep population is to survive and recover. We believe that the dwarf blue sheep needs to be placed in the Class 1 list of China's protected species.

The importance of religion is very useful to wildlife conservation in Ganzi. The Buddhist precept against

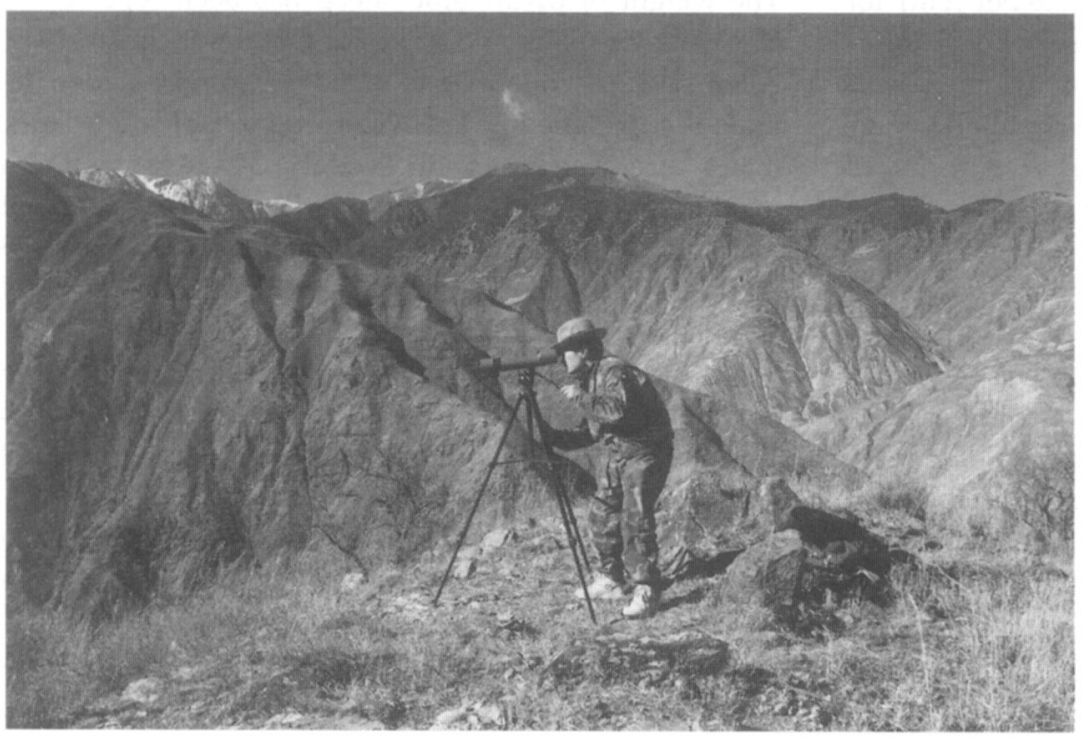

Plate 2 Biologist Hua-ming Zhou observing dwarf blue sheep in Batang (c) Xiao-ming Wang). 


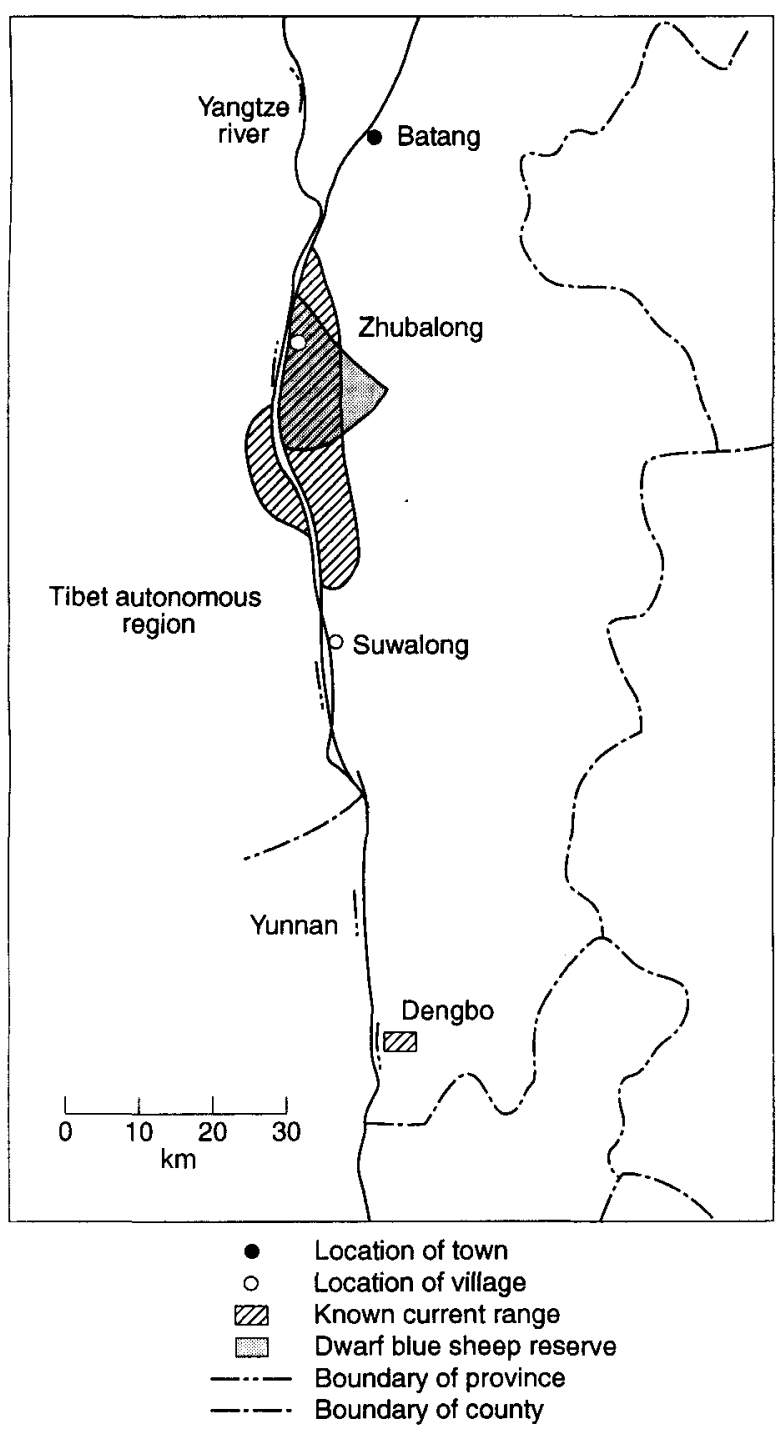

Fig. 2 The current distribution of dwarf blue sheep and its reserve, Batang County, Sichuan, China.

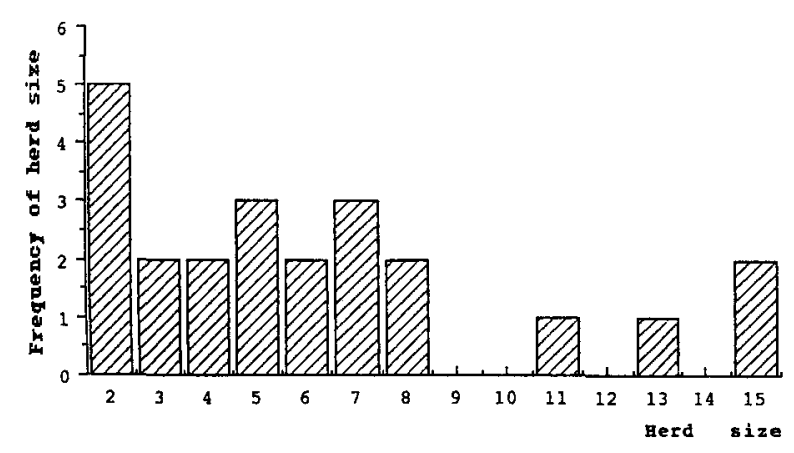

Fig. 3 Frequency of dwarf blue sheep herd size $(n=23$, mean $=$ $6.2 \pm 0.8 \mathrm{SE}$ ) observed during surveys in 1997 in Batang County, Sichuan, China. taking life is popular there because there are at least 400 monasteries in the prefecture. As Schaller et al. (1988) emphasized, an educational programme based on religious sentiment may encourage some poachers to lay down their arms. In addition, local TV and radio can be used to raise public awareness about wildlife conservation among local people. The Museum of Rare and Endangered Wildlife in the main administrative centre of Kangding already plays an important role in education, especially among local children.

\section{Acknowledgements}

Our work was part of a survey of large mammals in Ganzi Tibetan Autonomous Prefecture of Sichuan Province, funded with a grant from Fauna \& Flora International. We wish to thank all the individuals who took part in our survey, especially Ji-Zhong He, Wen-Fa Chau and Xin-Jian Yang of the Ganzi Forest Bureau. We are particularly indebted to Dr G. Schaller for encouragement, literature references and useful comments on an early draft of the manuscript. We also thank Dr David Shackleton for his help in revising the manuscript and an anonymous reviewer who provided valuable comments on an earlier version.

\section{References}

Allen, G.H. (1940) The mammals of China and Mongolia. In Natural History of Central Asia, Vol. II, No. 2. pp. 12681275. American Museum of Natural History, New York.

Anon (1994) The Forests of Ganzi Tibetan Autonomous Prefecture. Sichuan Dictionary Press, Chengdu [in Chinese].

Cai, C.P., Hu, J.C. \& Peng, J.T. (1990) The dwarf blue sheep of western Sichuan. Journal of East China Normal University (Mammalian Ecology Supplement), 90-95 [in Chinese].

Engelmann, C. (1938) Uber die gross säuger Szetschwans, Sikongs und Osttibets. Z. Säugetierkunde, 13, 1-76.

Groves, C.P. (1978) The taxonomic status of the dwarf blue sheep (Artiodactyla; Bovidae). Säugundliche Mitteilungen, $3,177-183$.

Haltenorth, T. (1963) Klassifikation des Säugetiere; Artiodactyla. Handbuch der Zoologie, Berlin, 8 Lfg, 32, $1-167$.

Hu, J.C. (1994) Rare Mammals of Sichuan. Sichuan Science and Technology Press, Chengdu [in Chinese].

IUCN (1996) 1996 IUCN Red List of Threatened Animals. International Union for Conservation of Nature, Gland, Switzerland.

Peng, J.T. (1995) The wildlife and forest reserves of Ganzi Tibetan Autonomous Prefecture. Joumal of Forest Science and Technology Ganzi, 1, 33-34 [in Chinese].

Shackleton, D.M. (1997) Wild Sheep and Goats and their Relatives: Status Survey and Conservation Action Plan. IUCN, Gland, Switzerland and Cambridge, UK. 
Schafer, E. (1937) Uber das Zwergblauschaf (Pseudois sp. nova) und das Grossblastoff (Pseudois nahoor Hags) in Tibet. Zool. Garten (N.F.), Leipzig, 9, 263-278.

Schaller, G.B. (1998) Wildlife of the Tibetan Steppe. University of Chicago Press, Chicago.

Schaller, G.B., Ren, J.R. \& Qiu, M.J. (1988) Status of the snow leopard Panthera uncia in Qinghai and Gansu Province, China. Biological Conservation, 45, 179-194.

Shi, B.N. \& Chao, E.M. (1982) Sichuan Fauna Economica. Sichaun People's Press, Chengdu [in Chinese].

Wang, X. \& Hoffman, R.S. (1987) Pseudois nayaur and Pseudois schaeferi. Mammalian Species, 278, 1-6.

Wang, S., Gu, J.H., Hu, D.F., Luo, N., Zhang, Y.Z., Wang, Z.Y et al. (1997) China, the Commonwealth of Independent States, and Mongolia. In Wild Sheep and Goats and their Relatives: Status Survey and Conservation Action Plan (ed. D. M. Shackleton), pp. 148-172. IUCN, Gland, Switzerland and Cambridge, UK.

Wu, Y., Yuan, C.G., Hu, J.C., Peng, J.T. \& Tao, P.L. (1990) A biological study of the dwarf blue sheep. Acta Theriologica Sinica, 10, 185-188 [in Chinese].

\section{Biographical sketches}

Xiao-ming Wang is currently Professor in the Department of Biology, East China Normal University of Shanghai, People's Republic of China and Secretary General of Shanghai Zoological Society. He received his $\mathrm{PhD}$ in Biology, Population and Ecology at the University of Montpellier II, France in 1993. His areas of interest include conservation biology, molecular ecology, animal behaviour, and ecology of endangered animal populations, particularly ungulate populations in China.

Ji-tai Peng is vice-head of Ganzi Prefecture Forest Bureau. He is a member of the IUCN/SSC/WPA Partridge, Quail and Francolin Specialist Group. He has led several teams including Japanese researchers investigating whitelipped deer and other deer throughout the prefecture. His current research focuses on local biodiversity conservation.

Hua-ming Zhou gained a BSC at South-western China Agricultural University and works in the Ganzi Prefecture Forest Bureau. He has published work on the biological control of rodents in Ganzi Prefecture. His interests are in biological resource conservation and sustainable use. 